\title{
HOUSEHOLD PERCEPTION AND RECYCLING BEHAVIOUR ON ELECTRONIC WASTE MANAGEMENT: A CASE STUDY OF KUALA-LUMPUR, MALAYSIA
}

\author{
Rulia Akhtar $^{1 *}$ Muhammad Mehedi Masud, and Rafia Afroz ${ }^{1}$ \\ 'Faculty of Economics and Management Sciences, International Islamic University, Malaysia, \\ ${ }^{2}$ Faculty of Economics and Administration, University of Malaya, 50603 Kuala Lumpur, Malaysia, \\ * Corresponding author E-mail: rulia.aktar@yahoo.com
}

\begin{abstract}
Electronic waste (e-waste) is increasing rapidly in Malaysia to the effect that e-waste management has now become a major environmental concern in Malaysia, especially Kuala Lumpur. In a step towards remedying this problem, this study seeks to ascertain household awareness, knowledge and risk perception of e-waste and its impact on attitudes and recycling behaviours in Kuala Lumpur. The result shows that three factors, namely, awareness, knowledge and risk perception of e-waste management have positive and significant influence on attitudes towards e-waste mangement. Furthermore, attitudes towards e-waste mangement has a positive influence on recycling behavior. This study provides valuable insights to policy makers so that they may take appropriate steps to increase recycling behaviour among households in Kuala Lumpur.
\end{abstract}

Keywords: Attitudes, Awareness, Electronic Waste, Recycling Behaviour and Risk Perception

\section{INTRODUCTION}

E-waste contains substantial metals for instance, Lead, Cadmium, Mercury, Barium, Arsenic, Berylium, Chromium and Selenium; halogenated compounds. Improper disposal of e-waste can pollute soil, groundwater, and might be dangerous for human beings and environmental health (Dwivedy \& Mittal, 2013). According to Herat \& Agamuthu (2012) that open burning for e-waste disposal may be threaten for public and environmental health. Electronic waste (e-waste) is said to be the fastest growing waste stream in the world (Nnorom \& Osibanjo 2008; Jain 2008; Cui \& Forssberg, 2003), with a growth rate of $3 \%$ to $5 \%$ per year (Mohan et al. 2008). The growth rate of ewaste is three times faster than that of general waste (Puckett et al., 2002, USEPA, 2011). This presents a formidable managerial challenge to developing and developed countries. Managing e-waste is a challenging task, not only due to its rapidly increasing volume, but also more importantly because of its hazardous nature. E-waste contains numerous hazardous substances, which may pose a threat to the environment and human health if they are not disposed of in the correct manner. On average, $9 \%$ of the weight of e-waste is made of hazardous substances such as lead, cadmium, mercury (heavy metals) and other toxic chemicals (Umweltbundesamt 2006; Sarkar 2008). Consequently, the management of e-waste continues to be a major challenge in Malaysia. Malaysia plays a dual role in e-waste trading - as an importer and exporter of e-waste. The geographic location of Malaysia, which lies in the middle of the international e-waste trade route, makes it an attractive target for e-waste smugglers. According to Puckett et al. (2002), Other than China, Malaysia receives e-waste from the USA, India, Pakistan, Vietnam, the Philippines, Nigeria, Ghana, Brazil and Mexico. Malaysia is also facing problems with rapid growth of domestic e-waste volumes generated from households, business entities and institutions. With a growing population living in urban areas and adopting modern lifestyles (due to economic transformation from agricultural-based to industrial-based socio-economies in the 1980s), the generation of domestic e-waste is expected to grow.

The volume of e-waste is expected to rise up to 1.1 million metric tones in 2020, at a rate of $14 \%$ annually (E-waste Inventory Project in Malaysia Report, 2009). From the year 2008 to 2020, it is projected that a cumulative total of 761.507 million units of e-waste in the seven categories will have been generated. In this period, the mobile phone rechargeable batteries (MPRB) show the highest contribution with a cumulative total of 257.168 million units followed by mobile phones with 199.594 million units. The least contributor to the ewaste projection between the years 2008 to 2020 is washing machines with a cumulative total of 10.24 million units only. The projection shown in Figure 1 
indicates that all e-waste included in this study generally increased from year to year since 1981 to 2020 with the exception of television sets and refrigerator. Mobile phone rechargeable batteries, computers and mobile phones show an increase pattern which reflects the standard population growth pattern in Malaysia. For mobile phones rechargeable batteries and mobile phones, both Ewastes indicate a similar pattern as shown in Figure 1.

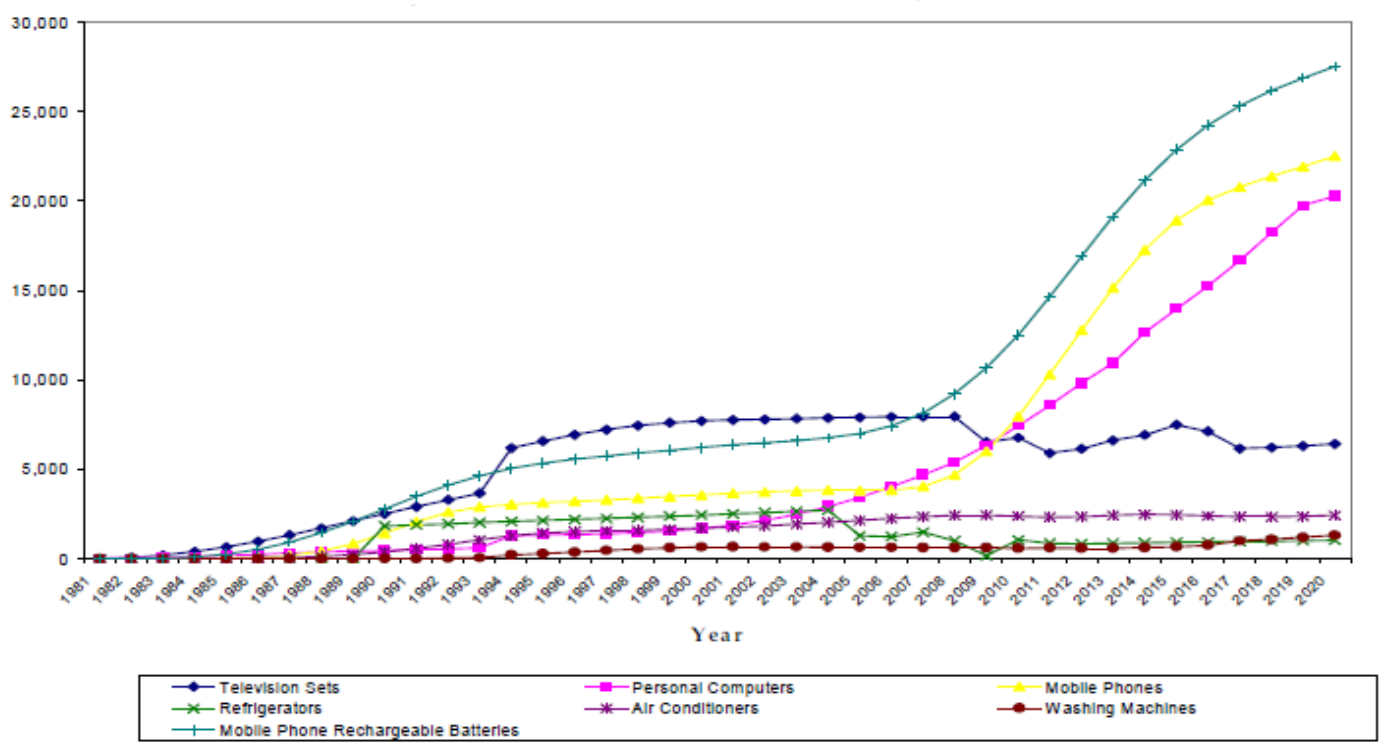

Figure 1. Projection of E-waste in Malaysia ('000 Units)

Source: E-waste Inventory Project in Malaysia Report, 2009

The rapid increase of discarded mobile phone rechargeable and mobile phones is influenced by the rapid replacement factor and also the pattern of continuous increase in the domestic sales.

As Malaysia is a large manufacturer and consumer of electronic appliances, since 2001 the Malaysian government has made efforts to tackle the problem caused by the recycling and disposal of e-waste. The development of small-scale and informal recycling processes has had serious adverse impacts on the environment and human health in some regions. These informal processes attract material from most of the e-waste generated and thereby become a barrier to formal recycling businesses. The importance of establishing a regulated e-waste management framework has been widely recognized but progress with regard to legislation, the collecting system and the construction of formal recycling facilities is slow. According to several studies ( Khetriwal et al., 2009; Gottberg et al., 2006; Yamaguchi, 2002; Lee et al., 2007), in order to boost EW recycling, one policy is often proposed; Extended Producer Responsibility (EPR) or 'take-back' policy. EPR, first proposed by
Lindhqvist in 1992, states that producers should extend their responsibility to the entire life of a product-not only to its production and sale, but also to the reclaiming and disposal of the end-of-life product (Lindhqvist, 1992). Furthermore, some electronic companies in Malaysia such as Dell, introduced an online recycling facility and receives all brands of computer and computer peripherals for free recycling, and offers payment for customers who recycle unwanted branded products. Other than that, Nokia and Motorola also adopt a selfgovernance mode by providing disposal facilities for users of their products.

The major problem facing Malaysian e-waste challenge is the attitude of Malaysians towards recycling (Mamat \& Chong, 2007). A survey carried out in 1999 showed that $59 \%$ of households were moderately aware with some basic knowledge and were mildly alert to solid waste issues (Irra, 1999). Therefore, recycling is argued to be a better solution to the problem of post-purchase of e-waste. Recycling is often considered an emerging trend, commencing with the greening of the society as a whole. Though recycling is a rather complex 
process that requires certain technological applications, it also incorporates a marketing aspect. In this sense, recycling is an issue of post-purchase consumer behaviour, as it is an activity that consumers undertake after a particular purchase has been made or even after the product of this purchase has been used. An analysis on future management of hazardous e-waste in Petaling Jaya, Malaysia, has shown that most people were aware of the hazardous materials present in electronic products but only a few actually knew the practices adopted to recycle their waste (Gatke, 2003). Furthermore, only few studies have been conducted regarding awareness, attitudes and recycling behaviour of the households in Kuala Lumpur.Hence, there is a need to identify and evaluate household perceptions regarding the appropriate e-waste management system in Malaysia.

\section{METHODOLOGY}

\section{Survey design and sampling methods}

The questionnaire used in this study was based on a survey among households in Kuala-Lumpur. The study employed direct face-to-face interviews because this has been shown to be the most reliable approach (Carson, Flores et al., 2001). The survey was conducted in August, 2013. Convenience sampling method was employed because the population is too large that it is impossible to include every individual. A total of 250 questionnaires were distributed in residential areas in Kuala Lumpur, i.e. Selayang, Cheras, Ampang, Taman Jaya and Kuala Lumpur. Of the 250, there were 200 acceptably completed questionnaires.

\section{Design of the questionnaire}

Questionnaires were the main instrument of data collection for this study. The questionnaire consisted of sections A and B. Section A collected information on the respondents' socio-economic characteristics such as gender, age, race, education, and income. Section B included several items to measure the respondents' perceptions, awareness, and attitudes towards e-waste and recycling behaviour.

\section{RESULTS AND DISCUSSIONS}

\section{Descriptive statistical analysis}

We successfully distributed 250 questionnaires among households and collected a total of 200 complete questionnaires. This shows a response rate of $80 \%$, where male respondents comprised of $50 \%$ and $50 \%$ female. The gender breakdown is shown in Figure 2

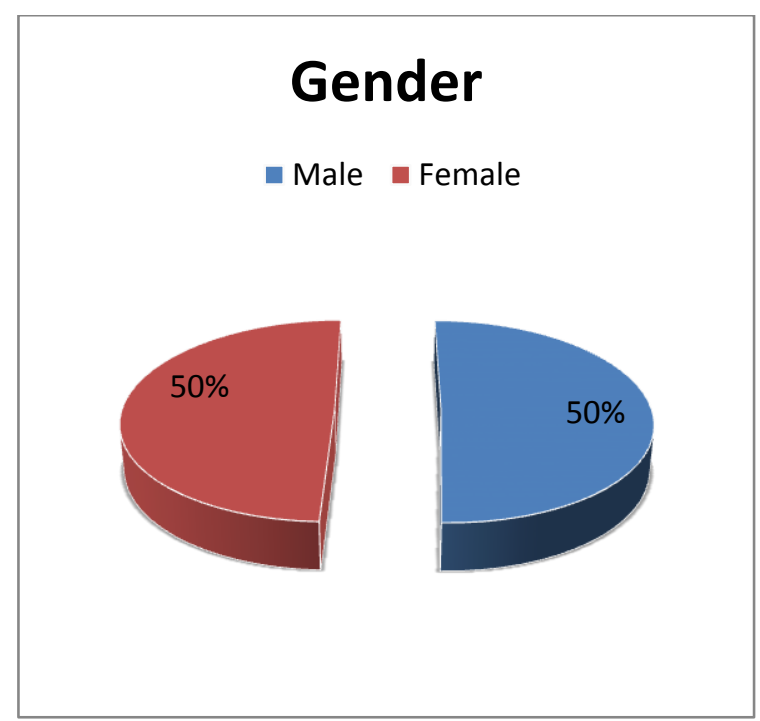

Figure 2. Sample of Study According to Gender

As for the age distribution of respondents, ages ranged between 18 and over 60 years. The greatest number of respondents (47.5\%) was from the $31-45$ age group. Most of the respondents are middle aged. The second largest group of respondents (40\%) was between 18-30 years. The age group breakdown is shown in Figure 3.

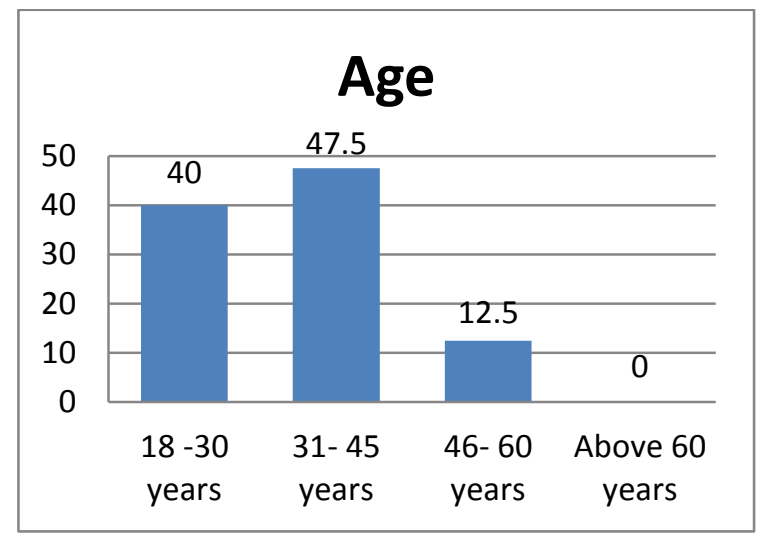

Figure 3. Sample of Study According to Age Group

In regards to ethnicity, the largest number of respondents was Malay $(61 \%)$, Indian (12\%), Chinese $(26 \%)$ and others $(1 \%)$. The nationality breakdown is shown in Figure 4 


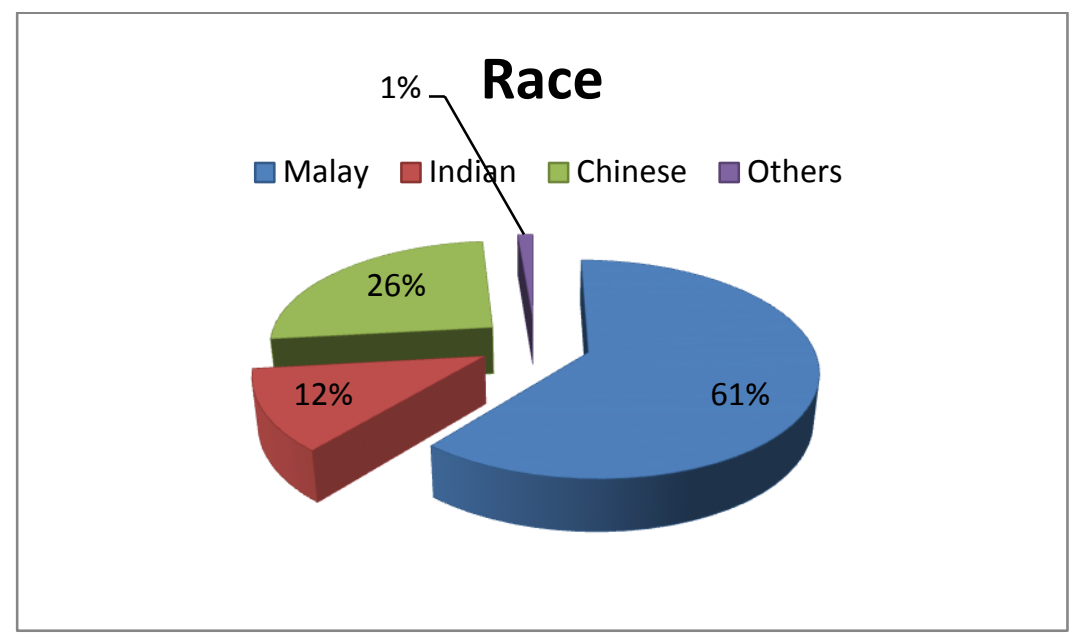

Figure 4. Sample of Study According to Nationality

The sample consists of different type of education level, the findings show that as for educational status, $22.5 \%$ had graduate education, while $22.0 \%$, $21.5 \%, 19 \%$ and $5.5 \%$ had diploma, lower secondary, higher secondary and postgraduate education, respectively. The education level breakdown of which is shown in Figure 5

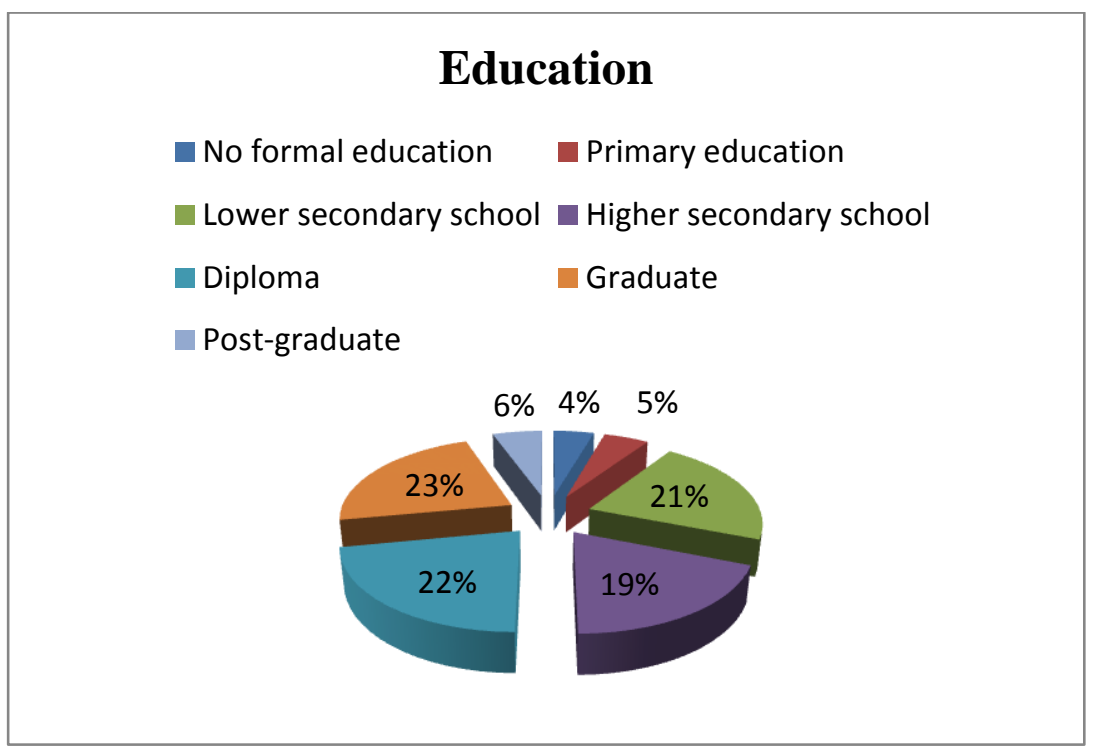

Figure 5. Sample of Study According to Level of education

The sample consists of different type of income level .This study found that only $8.5 \%$ of the respondents had income ranging from RM2000 and less than RM2000. The highest percentage of the respondents $(40.5 \%)$ had an income range of RM2000 up to RM4000 per month, while 39\%,
$7.5 \%$, of the respondents had an income range of RM4000 up to RM6000, and RM6000 up to RM8000 respectively. There were only $4.5 \%$ respondents with an income range of more than RM8000 per month. The income level is breakdown as shown in figure 6 


\section{Income}

RM 2000 and less than $\square$ RM 2,001- RM 4,000

$\square$ RM 4,001- RM 6,000 $\square$ RM 6,001- RM 8,000

$\square$ RM 8,001 and above

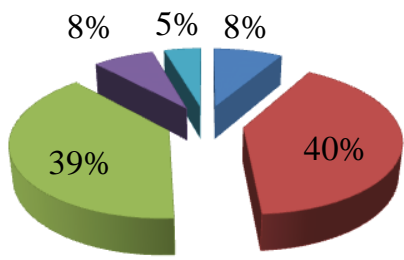

Figure 6. Sample of Study According to Income Level.

\section{Awareness of the hazards e-waste on the environment}

Due to rapid growth of advance technologies and a sharp decline in the price of electronic goods, people are using more electrical and electronic equipment, which has created a dangerous environmental problem. Based on our survey, $56 \%$ of the respondents know that the electrical and electronic equipment has created problems in the environment as well as human health. This is because they are very much conscious about their environment and the future generation. Only $44 \%$ of the respondents replied that they do not know about the environmental problem that can be created by electrical and electronic equipment. An analysis on future management of hazardous household waste in Petaling Jaya shows that most people were aware of the hazardous materials present in electronic products but only a few actually knew the practices adopted to recycle their waste (Gatke, 2003). Awareness of e-waste hazardous has significant effect on recycling practices (Saphores, Ogunseitan, \& Shapiro, 2012).

\section{Purchasing environmental friendly electronic equipment}

In modern era, people want to buy new technological and environmental friendly product in order to protect their environment. Nowadays, people are more conscious when they buy electrical and electronic equipment for their household. The respondents were asked whether they consider the environmental elements when they buy the electrical and electronic equipment for their household. In response to this question, $65 \%$ of the respondents answered "Yes", while $35 \%$ of the respondents answered "No". This means that people are aware about the dangerous effects of electronic equipment.

\section{Management of Electronic Products}

Presently, there are no household that does not use any electronic product. Almost all of the respondents use electronic products. With the development of new technologies, electronic products are becoming cheaper and easier to use. However, they also quickly become obsolete. Consumers sometimes find it comparatively cheaper and more convenient to buy new products rather than repairing old ones. When the electronic product becomes outdated and cannot be repaired, $34 \%$ of the respondents mentioned that they re-use their electronic product, while $30 \%$ of the respondents mentioned that they throw them in the waste bins and $27 \%$ of the respondents said they kept them in the house. On the other hand, only $3 \%$ and $2 \%$ of the respondents returned them to the manufacturer and recycling centre respectively (Figure 7). In Malaysia, there is no efficient takeback scheme for consumers. Currently, there is no structured mechanism to manage e-waste from households (Kalana, 2010). Extensive literature has proven that most consumers store their unused or broken electrical and electronic equipment for years before the equipment is resold or otherwise disposed of (Williams, 2005). 


\section{Percentage}

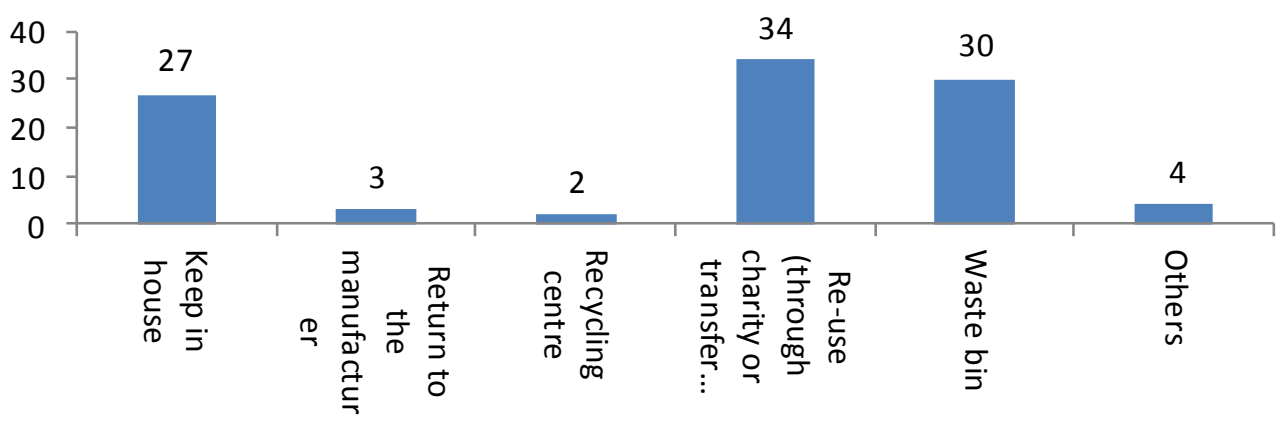

Figure 7. Electronic product becomes obsolete, what do you do with it?

\section{Tests for confirmatory factor analysis (CFA)}

According to Kline (2010), the purpose of a measurement model points to its appropriateness as a measurement instrument of the observed indicators representing a latent variable. This is echoed by Hair et al. (2010), who observed that in measurement theory, the purpose is to estimate the relationship between the observd and the underlying latent variables. The adequacy of a measurement model is performed by CFA. In doing so, four fit indices are checked to ascertain the fitting of the model with the data: chi-square statistic, normed chi-sqaure, root mean square approximation (RMSEA) and comparative fit index (CFI). For an adequate model fit, general guidelines suggest cutoff values for such indices: Normed Chi-Square and RMSEA are to be less than 5 and 0.088 respectively, while CFI values are to be above 0.9 (Hair el al., 2010; Byrne, 2010).Prior to testing the structural equation model, CFA was performed on the entire set of measurement items simultaneously.
The process of evaluating the measurement model resulted in deleting terms based on the factor loadings only factor loadings of less than 0.40 (Field, 2009). Based on the CFA tests, all five dimensions had adequate model-to-data fit: normed chi square value below 2.78; CFI value above 0.94 ; and RMSEA value less than 0.082. These tests also evaluated the reliability and construct validity. Cronbach's Alpha measures the reliability coefficient, which indicates the consistency of the entire scale (Hair, et al., 2010), or the overall reliability of the questionnaire (Field, 2009). The results from this study showed all five dimensions had reliability values above 0.70 which indicate that the questionnaire was reliable and consistent (see Table 1 below). According to Hair et al. (2010), a standardized factor loading should be 0.40 or higher, ideally 0.70 or higher, provides strong evidence of convergent validity. In this study, all the items had significant factor loadings, most of them greater than 0.60 , which indicates adequate convergent validity.

Table 1. Construct Validity of Confirmatory Factory Analysis

\begin{tabular}{lcc}
\hline Items & $\begin{array}{c}\text { Stand. } \\
\text { loadings }\end{array}$ & Reliability \\
\hline Awareness of hazards of $\boldsymbol{e}$-waste (Normed $\chi^{2}=2.30$, CFI $=0.965$, RMSEA & & \\
O.079) & 0.73 & 0.80 \\
I am aware of hazardousness of e-waste & 0.63 \\
I am aware that e-waste is serious problem for environment & 0.76 \\
I am aware that e-waste might affects human health & \\
Knowledge of hazards of $\boldsymbol{e}$-waste (Normed $\chi^{2}=1.56, C F I=0.925$, RMSEA $=$ & \\
O.061) & 0.57 \\
I know e-waste is rapidly increasing in Malaysia & 0.78 \\
E-waste has harmful effects for environment & 0.79 \\
E-waste might increase & \\
\hline
\end{tabular}


Table 1. Continued...

\begin{tabular}{|c|c|c|}
\hline Items & $\begin{array}{c}\text { Stand. } \\
\text { loadings }\end{array}$ & Reliability \\
\hline Recycling of e-waste has benefit to reduce GHG effects & 0.66 & \\
\hline \multicolumn{3}{|l|}{$\begin{array}{l}\text { Risk Perception of hazards of e-waste (Normed } \chi^{2}=1.46, C F I=0.922, \text { RMSEA } \\
=0.076)\end{array}$} \\
\hline E-waste is danger to public health & 0.64 & 0.78 \\
\hline E-waste has impacts on climate change & 0.62 & \\
\hline A more polluted atmosphere & 0.50 & \\
\hline \multicolumn{3}{|l|}{$\begin{array}{l}\text { Attitudes towards e-waste recycling (Normed } \chi^{2}=1.19, C F I=0.912, R M S E A= \\
0.070)\end{array}$} \\
\hline I'm willing to sort house hold waste into separate containers & 0.55 & 0.79 \\
\hline I will sort my household e-waste to protect the environment & 0.81 & \\
\hline $\begin{array}{l}\text { I'm willing to purchase environmental friendly product to reduce the impact of e- } \\
\text { waste on environment }\end{array}$ & 0.60 & \\
\hline \multicolumn{3}{|l|}{ Recycling behaviour $\left(\right.$ Normed $\left.\chi^{2}=2.41, C F I=0.935, R M S E A=0.070\right)$} \\
\hline I am practicing recycling & 0.60 & 0.74 \\
\hline I am willing to recycle e-waste to protect environment & 0.62 & \\
\hline It is my responsibility to encourage my neighbours to recycle e-waste & 0.64 & \\
\hline I am willing to implement recycling behaviour for my family & 0.67 & \\
\hline
\end{tabular}

\section{Test for Structural Equation Modeling (SEM)}

Structural equation modeling (SEM) is used to test the causal effect among the main constructs of a hypothesized model (Kline, 2010). In this study, a structural model was tested to examine the relationship among awareness of climate chnage, knowledge of climate chnage, risk perception of climate chnage, attitudes towards climate chnage and pro-environmental behaviour (see Figure 8 below). The model had an adequate fit to the data: chi square per degree of freedom $(10.83 / 4)=2.80$, less than 3; CFI $=0.910$, greater than $0.90 ; \mathrm{p}=$ 0.015 , less than $p \geq 0.005$; and RMSEA $=0.078$, less than 0.10 but greater than 0.088 (Hair et al., 2010).

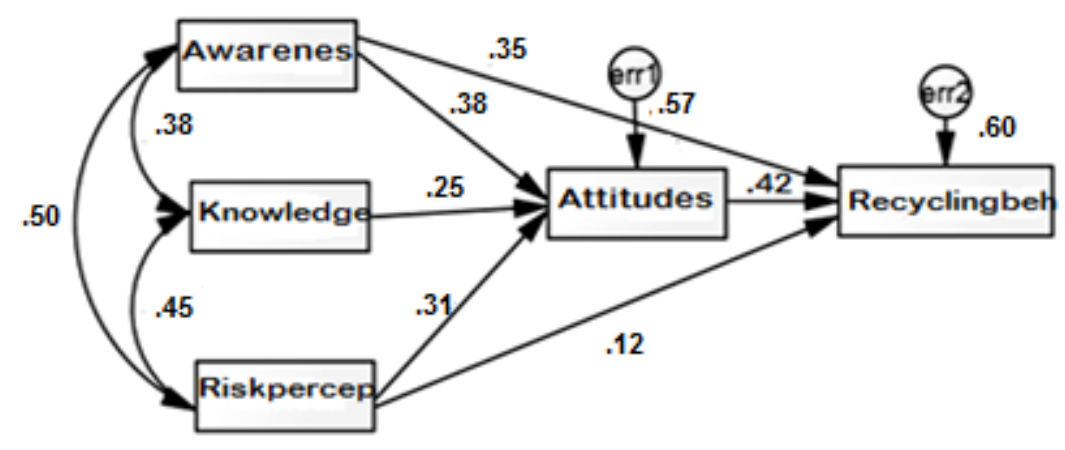

Figure 8. Structural equation modeling of e-waste and recycling behaviour 
As shown in Figure 8, the $\mathrm{R}$ square for the two dependent (endogenous) variables were recycling behaviour $=0.60$ and attitudes towards climate chnage $=0.57$, which indicated that a large percentage of the variance in the dependent factors was explained by the independent (exogenous) factors. All hypotheses were supported in the SEM based on the significant level $(\mathrm{p}=<0.001)$ except hypothesis six (see Table 2 below).

Table 2. Hypothesised Path Coefficients

\begin{tabular}{llccc}
\hline Hypothesized paths & $\begin{array}{c}\text { Coefficient } \\
(\beta)\end{array}$ & $\begin{array}{c}\text { P-value } \\
(\text { sig.) }\end{array}$ & Remarks \\
\hline H1 & Awareness $\rightarrow$ attitudes towards e-waste recycling & 0.381 & 0.000 & Supported \\
H2 & Knowledge $\rightarrow$ attitudes towards e-waste recycling & 0.250 & 0.000 & Supported \\
H3 & Risk perception $\rightarrow$ attitudes towards e-waste recycling & 0.311 & 0.000 & Supported \\
H4 & Attitudes towards climate chnage $\rightarrow$ Recycling behaviour & 0.421 & 0.000 & Supported \\
H5 & Awarenes $\rightarrow$ Recycling behaviour & 0.351 & 0.000 & Supported \\
H6 & Risk perception $\rightarrow$ Recycling behaviour & 0.121 & 0.109 & Unsupported \\
\hline
\end{tabular}

The SEM model shows that three factors, such as awareness of hazards e-waste $(\beta=0.381)$, knowledge of hazards of e-waste $(\beta=0.250)$ and risk perception of hazards of e-waste $(\beta=0.311)$, have positive and significant influence on attitudes towards e-waste recycling. The SEM results also shows that attitudes towards e-waste recycling has positive and significant influence on recycling behavior $(\beta=0.421)$.

\section{CONCLUSION AND RECOMMENDATIONS}

It was found that large numbers of the respondents do not know e-waste has created problems in the environment as well as human health. Therefore, there is a need for an educational campaign to disseminate and increase awareness among households. It is essential to improve elementary education in environmental protection and resource conservation to foster the e-waste recycling behaviour from childhood. Awareness of hazards of e-waste is very important to practice recycling behavior. There are numerous studies indicaing that awareness, knowledge and perception influence public positive attitudes (Natura 1995; Jim \& Xu 2002). Lin (2012) found that attitudes influence proenvironment behavioural intentions. Therefore, we could conclude based on findings that awareness, perception and knowledge have a greater impact on human attitudes that might lead to behavioural changes. In addition, there is a need to have a better understanding of the role of social adaptation such as information dissemination, involvement with organizations and associations. This could offer more insights and lead to group improvement in order to have acceptable and effective recycling behaviour. The results indicate that the importance of social interaction in knowledge sharing has an influence on the attitude towards recycling behaviour. Hence, mass media is contributing significantly by informing mass audience regarding the hazards of e-waste. Thus, policy makers and communicators confront great tasks to promote public awareness, to encourage proper behaviours towards recycling (Weingart, Engels et al., 2000). To date, there are partial achievements in employing with the provision set by the United Nations Framework Convention on climate change (UNFCCC) on increasing public awareness, training and information diffusion to enlighten the public about the impact of climate change on their livelihood (Alam \& Rabbani 2007). Patchen (2006) identified that knowledge and attitude towards the environment depends on several individual characteristics (for example age, sex, education) and societal inspirations (Song et al., 2012).

\section{REFERENCES}

1. Alam, M., \& Rabbani, M. G. (2007). Vulnerabilities and responses to climate change for Dhaka. Environment and Urbanization, 19(1), 81-97.

2. Byrne, M., Soars, N. A., Ho, M. A., Wong, E., McElroy, D., Selvakumaraswamy, P.,\& Davis, A. R. (2010). Fertilization in a suite of coastal marine invertebrates from SE Australia is robust to near-future ocean warming and acidification. Marine biology, 157(9), 2061-2069. 
3. Carson, R., Flores, N., Meade, N.F. (2001). Contingent valuation: controversies and evidence. Environmental and Resource Economics. 19, 173-210

4. Cui, J., and Forssberg, E. (2003). Mechanical Recycling of Waste Electric and Electronic Equipment: A Review. Journal of Hazard Material..99, 243- 263.

5. Dwivedy, M., \& Mittal, R. K. (2013). Willingness of residents to participate in e-waste recycling in India. Environmental Development, 6, 4868.

6. E-waste Inventory Project in Malaysia Report, (2009).

7. Field, A. (2009). Discovering statistics using SPSS. Sage publications

8. Gatke, P. (2003). Future Managament of Hazardous Household Waste in Petaling Jaya: A preliminary assessment, DUCED- MUCED I\&UA Report.

9. Gottberg, A., Morris, J., Pollard, S., Mark-Herbert, C., Cook, M. (2006). Producer responsibility, waste minimisation and the WEEE directive: case studies in ecodesign from the European lighting sector. Sci. Total Environ. 359, 38-56.

10. Hair, J. F., Black, W. C.,Babin, J. B., \& Anderson, R. E. (2010). Multivariate Data Analysis. ( th $^{\text {ed.). }}$. Upper Saddle River, NJ: Prentice Hall.

11. Herat, S., Agamuthu, P., 2012.Ewaste: a problem or an opportunity? Review of issues, challenges and solutions in Asian countries. Waste Management \& Research30 (11), 1113-1129.

12. Irra, M.S. (1999). Sustainable waste management: an awareness study on cleaner technologies in the Klang
Valley. Master's Thesis, University of Malaya.

13. Jain, A. (2008). Global E-waste Growth. In Johri, R., ed. E-waste. Implication, Regulations, and Management in India and Current Global Best Practices. New Delhi, India: TERI Press. pp.3-22.

14. Jim, C. \& Xu S.S. (2002). Stifled stakeholders and subdued participation: interpreting local responses toward Shimentai Nature Reserve in South China. Environmental Management 30(3): 327-341.

15. Kelana A.J. (2010). Electrical and Electronic Waste Management Practice by households in Shah Alam, Selangor, Malaysia. International Journal of Environmental Science. 1, 132-144

16. Khetriwal, D.S., Kraeuchi, P., Widmer, R. (2009). Producer responsibility for e-waste management: key issues for consideration e learning from the Swiss experience. Journal of Environmental Management. 90, 153165.

17. Kline, R. B. (2010). Principles and practice of structural equation modeling, Guilford press.

18. Lee, J.C., Song, H.T., Yoo, J.M. (2007). Present status of the recycling of waste electrical and electronic equipment in Korea. Resour. Conservat. Recycl. 50, 380-397.

19. Lindhqvist, T. (1992). Towards an Extended Producer ResponsibilityAnalysis of Experiences and Proposals. Ministry of the Environment and Natural Resources, Stockholm.

20. Lin, S. P. (2012). The gap between global issues and personal behaviors: pro-environmental behaviors of citizens toward climate change in Kaohsiung, Taiwan. Mitigation and 
Adaptation Strategies for Global Change, 1-11

21. Mamat, R.C., Chong, T.L. (2007). Public's role in solid waste management: in IMPAK, quarterly DOE update on environment. Development and Sustainability (4), 5-7

22. Mohan, M.P.R., Garg, I., and Kumar, G. (2008). Regulating e-waste: a review of the international and national legal framework on e-waste. In Johri, R., ed. E-waste.Implication, Regulations, and Management in India and Current Global Best Practices.New Delhi, India: TERI Press. Pp.169-188.

23. Natura, F. (1995). Local communities and protected areas: attitudes of rural residents towards conservation and Machalilla National Park, Ecuador. Environmental Conservation22 (3).

24. Nnorom, I.C. and Osibanjo,O. (2008). Electronic waste (e-waste): Material flows and management practices in Nigeria. Waste Management.28, 1472 -1479 .

25. Patchen, M. (2006). Public attitudes and behavior about climate change: what shapes them and how to influence them. East Lafayette, Indiana, University of Purdue.

26. Puckett, J.,Byster, L., Westervelt, S., Gutierrez, R., Davis, S., Hussein, A., Dutta, M.(2002). Exporting Harm: The High-tech Trashing of Asia.Seattle: The Basel Action Network and Silicon Valley Toxic Coalition. Available from: http://ban.org/Ewaste/technotrash finalcomp.pdf . [Accessed 23 March 2010].

27. Sarkar, A. (2008). Occupational and Environmental Health Perspectives of Ewaste Recycling in India: A Review. In Johri, R., ed. E-waste. Implication,Regulations, and Management in India and Current
Global Best Practices.New Delhi, India: TERI Press. pp.169-188.

28. Song,.,Wang,Z.,Li,J.,2012.Residents' behaviors, attitudes, and willingness to pay for recycling e-waste in Macau. Journal of EnvironmentalManagement106,8-16.

29. Umweltbundesamt, Anderl, M. and Freudenschuss, A. (2006). Austria's National Inventory Report 2006. Submission under the United Nations Framework Convention on Climate Change (UNFCCC). Report, Bd. REP0016. Umweltbundesamt, Wien.

30. USEPA (U.S. Environmental Protection Agency), 2011. Electronics Waste Management in the United States through 2009 (EPA 530-R-11002). Washington, DC.

31. Weingart, P., Engels, A., \& Pansegrau, P. (2000). Risks of communication: discourses on climate change in science, politics, and the mass media. Public understanding of science, 9(3), 261-283.

32. Williams, P. (2005). Waste Treatment and Disposal. Chichester: Wiley.

33. Yamaguchi, M. (2002). Extended producer responsibility in Japan: introduction of 'EPR' into Japanese waste policy and some controversy. Journal of Environmental Management. Assoc. Ind. (JEMAI) ECP Newsl. 19. 